\title{
Condition monitoring of induction motor bearing based on bearing damage index
}

\author{
R.K. PATEL, V.K. GIRI \\ Department of Electrical Engineering, \\ Madan Mohan Malaviya University of Technology \\ Gorakhpur-273 010, India \\ e-mail: rajkp007@gmail.com
}

(Received: 07.07.2015, revised: 19.10.2016)

\begin{abstract}
The rolling element bearings are used broadly in many machinery applications. It is used to support the load and preserve the clearance between stationary and rotating machinery elements. Unfortunately, rolling element bearings are exceedingly prone to premature failures. Vibration signal analysis has been widely used in the faults detection of rotating machinery and can be broadly classified as being a stationary or non-stationary signal. In the case of the faulty rolling element bearing the vibration signal is not strictly phase locked to the rotational speed of the shaft and become "transient" in nature. The purpose of this paper is to briefly discuss the identification of an Inner Raceway Fault (IRF) and an Outer Raceway Fault (ORF) with the different fault severity levels. The conventional statistical analysis was only able to detect the existence of a fault but unable to discriminate between IRF and ORF. In the present work, a detection technique named as bearing damage index (BDI) has been proposed. The proposed BDI technique uses wavelet packet node energy coefficient analysis method. The well-known combination of Hilbert transform (HT) and Fast Fourier Transform (FFT) has been carried out in order to identify the IRF and ORF faults. The results show that wavelet packet node energy coefficients are not only sensitive to detect the faults in bearing but at the same time they are able to detect the severity level of the fault. The proposed bearing damage index method for fault identification may be considered as an 'index' representing the health condition of rotating machines.
\end{abstract}

Keywords: bearing damage index (BDI), inner raceway fault (IRF), outer raceway fault (ORF), fault severity, vibration signal

\section{Introduction}

Rotating machinery is an essential component in most of today's manufacturing and production industries. Fault detection techniques for rotating machinery were studied by numerous researchers with an objective of reducing operational and maintenance costs besides preventing unscheduled downtimes [1-2]. Bearing failure can take place because of many reasons such as wear, contamination, and improper installation. One of the common modes of failure 
in a rolling element bearing is a point defect on the inner or outer raceway of the bearing [3]. Such defects produce a series of impacts in a vibration signal. When a running roller passes over the surface of the defects, a fault of a different impact will appear, with different frequencies. The magnitude of frequencies is often lost in the general background noise when the degree of damage is small, but because of their precise nature, they present an effective route for monitoring of progressive bearing degradation. To detect such faults in bearings, many kinds of methods have been developed so far [4-6]. One of the widely used methods for failure detection and diagnosis of the rotating machines is vibration analysis. This recorded vibrational signal is usually non-stationary, non-linear, and with strong noise interference. The feature extraction of these vibration signals is a very important and difficult research task [7-8].

A machine in standard condition has certain vibration signatures. These signatures are modulated by a number of high-frequency harmonic components resulting from structural response to individual impacts. Fault development changes these signatures in a way which may be related to these faults. This has given rise to the term 'mechanical signature analysis' [9]. To make a proper maintenance decision for rotating machinery it is helpful to know the health condition and severity (size) of the fault during operation [10]. S. Wadhwani et al., E. CabalYepez, and Choudary et al., suggested that as the fault increases in severity, the magnitude of the broadband changes in the machine vibration increases accordingly [11-13].

Any recorded signal may be analyzed in a time domain, frequency domain, and time-frequency domain. The selection of a proper signal processing technique is important for extracting the fault- related information. The time domain analysis mainly uses the parameters like RMS value, a peak factor, a crest factor, a skewness and kurtosis [14]. Among these, the kurtosis has been found to be very effective. Time domain information, however, is mostly rich in content with little useful information. In the frequency domain approach, major frequency components of the vibration signals and their amplitude are used for trending purposes. The frequency characteristics of the vibration for a defective bearing subjected to various load condition have been investigated [15]. Time-frequency domain techniques have been proposed including Short-Time Fourier Transform (STFT), the Wigner-Ville Distribution (WVD), and the Wavelet Transform (WT) [16-17].

However, most of such methods only identify the fault type and location, lacking a quantitative index to describe the fault severity which is the basis of the condition base maintenance [18]. A quantitative method for a fault diagnosis method is required to describe the evolution of fault location and identifying the fault size. Hong and Liang studied the damage degree of the rolling bearing in the single damage cases under the experimental simulation based on continuous wavelet and Lempel-Ziv indicators [19].

The bearings in rotating machinery should be periodically checked with a frequency spectrum and time signal in order to detect and study the emergent defects on the outer and inner races. An accurate method for the calculation of bearing defect length is needed to allow the quantitative determination of the defect severity. The remaining bearing life may be estimated based on the defect size and progression of development of the fault.

In the present work, the bearing vibration signal is taken only to diagnose the faults in the bearing part and develop an improved method to identify the bearing fault for rotating ma- 
chinery based on a calculation of a bearing damage index (BDI) in the time-frequency domain. In this method, the energy of the decomposed and reconstructed signal is calculated by using the Wavelet Packet Transform (WPT) on different fault severity level. Then we have calculated the percentage variation of wavelet energy which is termed as a bearing damage index (BDI). In the further section of the paper details of measured data, specification, the analysis in time, frequency and time-frequency domain analysis have been presented. The results obtained have been analyzed for different severity level using envelope spectra analysis.

\section{Machinery specification and vibration data}

In the present study, bearing vibration records have been selected from the Case Western Reserve University Lab data center for analysis and faults recognition [20]. The analysis is applied to a 6205 SKF deep-groove ball bearing and this bearing is used as motor shaft support at the drive end of a $2 \mathrm{HP}$, three-phase induction motor. The accelerometer was mounted on the motor housing at the drive end of the motor. The samples have been taken at 12000 per second for each of a 16-channel digital audio tape (DAT) recorder. The speed of the shaft is measured as 1797 and $1752 \mathrm{rpm}$ from no load to full load respectively. The specifications of the bearing are: numbers of balls are 9 , the ball diameter is $7.94 \mathrm{~mm}$, the pitch diameter is $39.04 \mathrm{~mm}$ and a contact angle is $0^{\circ}$. Single point faults were introduced to the test bearings using electro-discharge machining. The seeded fault sizes in the bearing are 0.007 inches and 0.021 inches in diameter with the depth of 0.011 inches each.

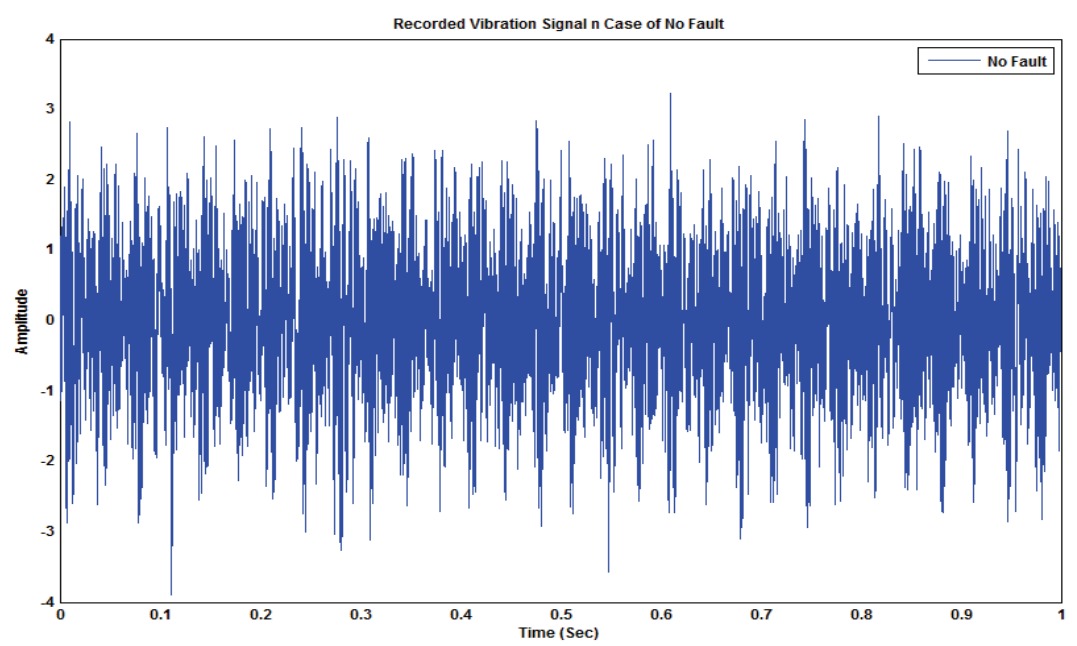

Fig. 1. Vibration signal for normal bearing

The vibration signature of a normal bearing is shown in Fig. 1. The vibration signature for faulty bearings with the located fault in the inner raceway and outer raceway are shown in Figs. 2 and 3 with the superimposed fault level of 0.007 inches and 0.021 inches diameter 
[20]. From the visual image of the vibration, repetitive impacts may be observed corresponding to the rotation of the rolling elements past the race damage.

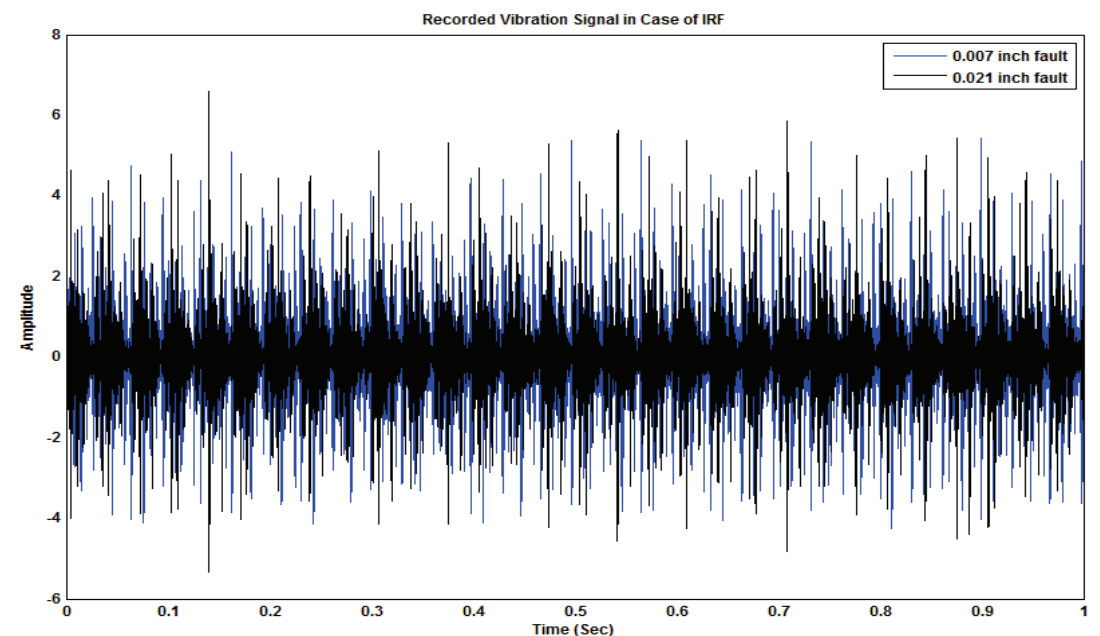

Fig. 2. Vibration signal for inner race fault

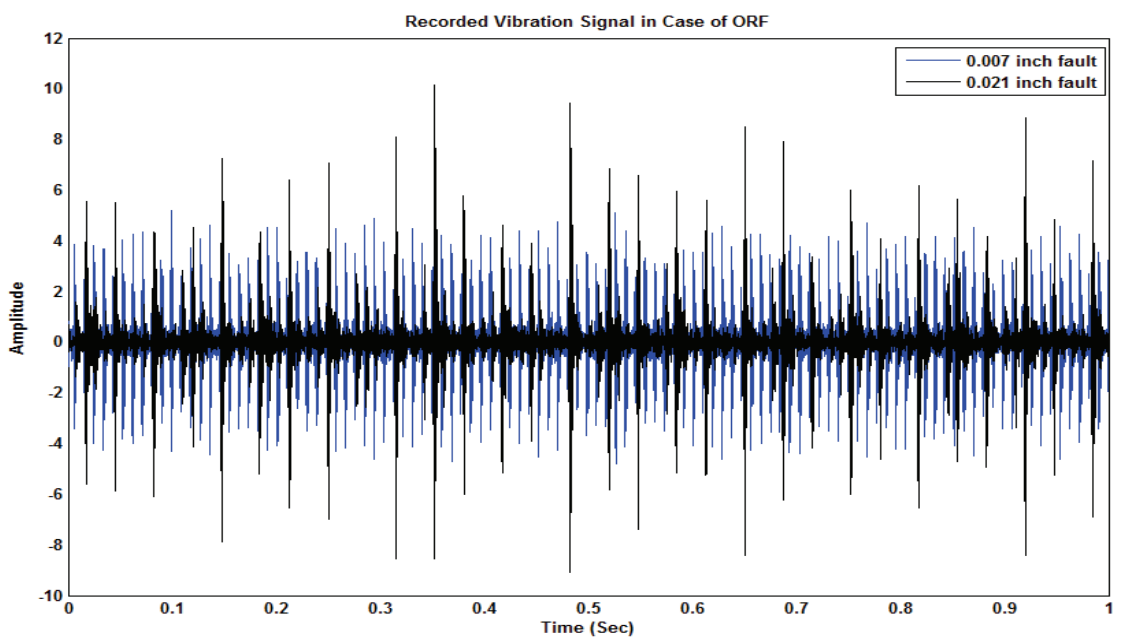

Fig. 3. Vibration signals for outer race fault

\section{Statistical analysis}

One of the simpler detection and diagnosis approaches is to analyze the measured vibration signal in the time domain. The simplest, though not the most reliable way to detect faults in machines, is to compare their vibration levels with standard criteria for the vibration severity. 
In the time domain analysis, first, we use the probability density distribution function $p(x)$ of the vibration signal. The probability density of the distribution of a data sample is defined as:

$$
\operatorname{prob}[x \leq x(t) \leq x+d x]=p(x) d x .
$$

Since, the vibration of a normal bearing consists of the combination of numbers of separate independent effects, the central limit theorem indicates that its probability density will tend towards a Gaussian curve (bell shaped).

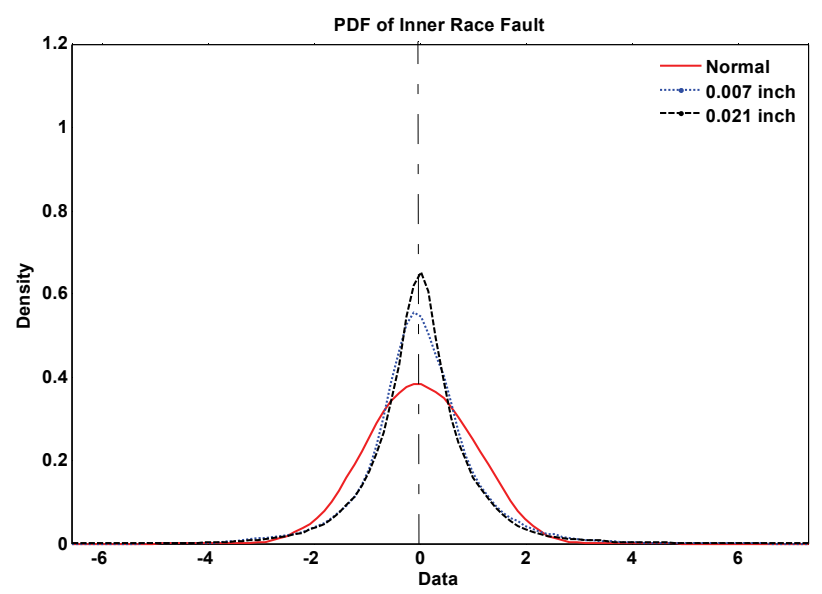

Fig. 4. Probability density distribution of IRF

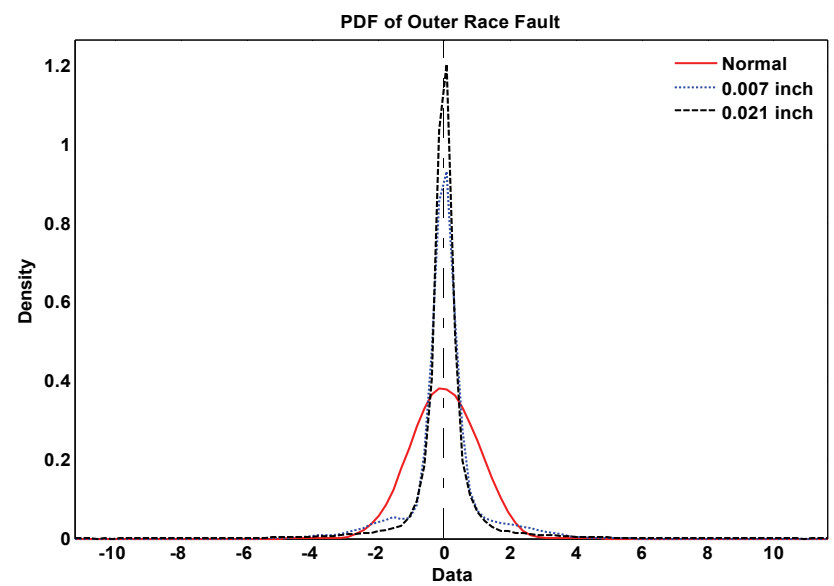

Fig. 5. Probability Density Distribution of ORF

The probability density of acceleration of a bearing in good condition has a Gaussian distribution, whereas a deterioration and damaged bearing lead to non-Gaussian distribution with dominant tails because of a relative increase in the number of high levels of acceleration [21]. This theoretical prediction is confirmed in practice. Figs. 4 and 5 show the probability density 
distribution of a bearing in normal condition and with a case of a fault in IRF, ORF conditions. The taken fault sizes are 0.007 and 0.021 inches in diameter, the figure also exhibits that when the fault severity increases the probability density distribution become more non-Gaussian with the dominating tail. Mathew and Alfredson [22] reported similarity after obtaining a near-Gaussian distribution for some damaged bearings and the same is observed in the case of the probability density distribution of IRF shown in Fig. 4, which, some times, may be taken as a healthy bearing.

Hence, instead of studying the probability density distribution curves, it is often more informative to examine the statistical parameters. Time domain numerical parameters have been used as a trend to detect the presence of incipient bearing damage. In this paper, the stated statistical parameters have been categorized as follows:

- measure of moments and

- dimensionless quantity of the data.

Mathematically the above may be calculated or expressed as follows:

First moment

$$
\mu_{\text {mean }}=\frac{1}{N} \sum_{i=1}^{N}\left|x_{i}\right| .
$$

Second moment

$$
\sigma_{\text {varience }}^{2}=\frac{1}{N} \sum_{i=1}^{N}\left(x_{i}-\bar{x}\right)^{2} \text {. }
$$

Third moment

$$
\gamma_{\text {skewness }}=\frac{\frac{1}{N} \sum_{i=1}^{N}\left(x_{i}-\bar{x}\right)^{2}}{\sigma^{3}} .
$$

Fourth moment

$$
\gamma_{\text {kurtosis }}=\frac{\frac{1}{N} \sum_{i=1}^{N}\left(x_{i}-\bar{x}\right)^{4}}{\sigma^{4}}-3 .
$$

Crest factor

$$
X_{c f}=\frac{\max \left(\left|x_{1}^{2}\right|\right)}{\left(\frac{1}{N} \sum_{i=1}^{N} x_{1}^{2}\right)^{1 / 2}} .
$$

Impuls factor

$$
X_{i f}=\frac{\max \left(\left|x_{i}\right|\right)}{\frac{1}{N} \sum_{i=1}^{N}|x|} .
$$

Margin factor

$$
X_{m f}=\frac{\max \left(\left|x_{i}\right|\right)}{\left(\frac{1}{N} \sum_{i=1}^{N} \sqrt{x_{1}}\right)^{2}} .
$$


Shape factor

$$
X_{c f}=\frac{\left(\frac{1}{N} \sum_{i=1}^{N} x_{1}^{2}\right)}{\frac{1}{N} \sum_{i=1}^{N}\left|x_{1}\right|},
$$

where $X_{i}$ is the data set and $N$ is the total number of samples.

A Measure of moments as; first and second moments are well known, being the mean value and the variance respectively. The third moment normalized with respect to the cube of standard deviation is known as the coefficient of 'skewness'. The fourth moment, normalized with respect to the fourth power of standard deviation is known as 'kurtosis' [23]. The equation (2) to (5) belongs to the measure of moments. The dimensionless quantities which include a crest factor, impulse factor, margin factor and shape factor have been calculated using Equation (6) to (9). These statistical parameters may be used to perform a quick check of the changes in the statistical behavior of the signal [24].

Figs. 6 and 7 show a three-dimensional (3D) graph of IRF and ORF at two different stages of the fault. In the 3D figure, the amplitude of measures is compared with increasing fault severity for IRF and ORF. The graph shows that the dimensionless quantity and the kurtosis (fourth moment) are more effective to investigate the fault severity level because of a significant improvement in amplitude with the increasing fault diameter. However, numerical parameters can only be used for estimating the fault severity but are unable to differentiate between the IRF and ORF because the measures of the amplitude are display increasing nature in both types of the fault.

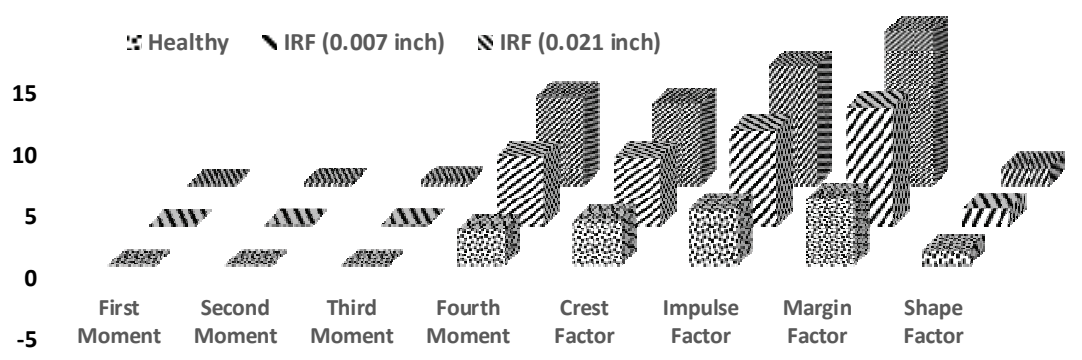

Fig. 6. A $3 \mathrm{D}$ plot showing the behavior of statistical parameters for healthy and inner race fault (IRF)

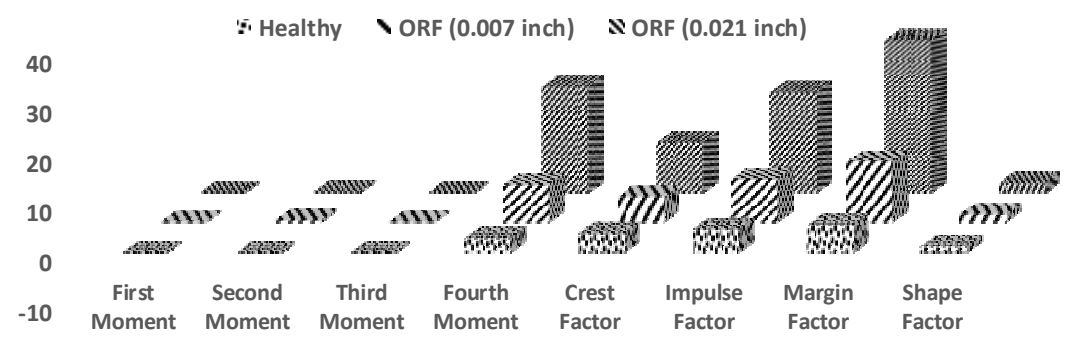

Fig. 7. A 3D plot showing the behavior of statistical parameters for healthy and outer race fault (ORF) 


\section{Bearing damage index based envelope power spectrum}

The main drawback of the time domain analysis is an inability to identify the location of faults. In the frequency domain, these faults are characterized by significant peaks at periodic intervals but they are of low energy. These signals are modulated by a number of high-frequency harmonic components, subsequently from the structural response to individual impacts. Due to this, the characteristics frequencies are missing in the noise. The characteristics frequencies are shown in Table 1. How to extract the fault features and identify the condition from vibration signals are the key steps in the fault diagnosis of rotating machinery. Signal processing is an approach broadly used in diagnostics since it allows directly characterizing the state of the system. Several types of advanced technique have a different theoretical basis, the results obtained are usually different. Some techniques may be more suitable than others for a specific system component, depending on the environmental conditions. Therefore, it is important to choose techniques that are the most effective for the case and situation under testing for a reliable diagnosis.

The limitation of the FFT led to the development of the joint time-frequency analysis technique, in which a wavelet transform is giving information in both time and frequency domains. The wavelet transform can be considered as a mathematical tool which is further extended as Wavelet Packet Transform (WPT). The WPT is a development of wavelet decomposition that offers a richer range of possibilities for the signal analysis [25]. This analysis is obtained as a result of successive time localization of frequency sub-bands generated by a tree of low pass and high pass filter operations. The enhanced signal decomposition capability in the high-frequency region makes WPT an attractive tool for detecting and differentiating transient components with high- frequency characteristics. Wang and Zhang [26] extensively studied on the Wavelet Packet Transform (WPT) and envelope analysis for rolling bearing fault diagnosis. However, the demodulation property of these methods is limited by the degree of damage of the bearing.

In order to explore fault feature information, WPT may be used to divide finer frequency ranges. The finer frequencies ranges are known as sub-bands. Each sub-band covers one eight of the frequency information successfully. Therefore, a WPT-based method is proposed for the damage assessment of a bearing in the present study. The Daubechies family db10 has been used as a mother wavelet for wavelet packet analysis. The further energy of each subband has been calculated using Parsvel's theorem. The objective of the proposed method is to estimate a quantity based on WPT energy called bearing damage index (BDI) as well as to identify the WPT sub-band which contains maximum fault information.

One of the most prominent vibration signal processing techniques for the detection and diagnosis of early faults in the rolling element is envelope analysis, originally called the highfrequency resonance technique. For instance, when a rolling element contacts a defect on the inner or outer raceway, it produces an impact which in turn excites the structural modes of the bearing and its support. If a bearing has a spall type of defect on the raceway, every time a rolling passes through the spall, it would generate an impact with relatively large amplitude and decay exponentially according to the damping characteristics of the structure [27]. 
Therefore, the overall vibration signal measured on the bearing shows a pattern consisting of a succession of oscillating bursts dominated by the major resonance frequency of the structure. The process of demodulating the vibration signals of the resonance condition is known as envelope analysis which finally results in the excitation of an impulse. This impulse not only detects the presence of a fault but also localizes the component of the fault. It provides a mechanism for extracting out the periodic excitation of the resonance from vibration signals.

The procedure of envelope analysis is as follows: first, calculate the envelope signal $y(t)$ by applying Hilbert transform (HT) to vibration signal $x(t)$;

$$
y(t)=\sqrt{x^{2}(t)+H^{2}[x(t)]} .
$$

The envelope signal of $x(t)$ is simply the absolute value of the analytic signal $|y(t)|$.

The Hilbert transform can be said to be the relationship between the real and imaginary parts of the FFT of a one-sided function. Assume a piece of signal $x(t)$ its Hilbert transform $H[x(t)]$ which is defined as:

$$
H[x(t)]=\frac{1}{\pi} \int_{-\infty}^{+\infty} \frac{x(\tau)}{t-\tau} \mathrm{d} \tau,
$$

where, $t$ and $\tau$ are time and translation parameters, respectively.

The next step is to go for Fourier Transform of the envelope signal in order to get the frequency domain information and calculate the spectrum.

Step for calculating BDI based enveloped power spectrum demonstrated as follows:

1) Take the measured healthy and faulty signals of IRF and ORF at 0.007 and 0.021 inches for each diameter of a fault.

2) Decompose all five signals using WPT up to level three.

3) Reconstruct each node using Db10 coefficients.

4) Calculate node energy $E_{i}(I=1,2,3 \ldots .8)$ for one healthy and four faulty signals.

The energy of each node reconstructed signal can be obtained by

$$
E_{i}=\sum_{i=1}^{N}\left|x_{1}\right|^{2},
$$

where, $N$ is the number of the sample in the reconstructed signal.

5) Calculate the percentage of the damage with the help of the bearing damage index (BDI) as shown in the flow chart.

6) Select a higher index node for identification of bearing characteristic frequency. Because the resonant vibration existing in a higher node energy,

7) Perform Hilbert transform to obtain analytical signal $y(t)$.

8) Perform spectrum analysis of signal $y(t)$.

9) Identify theoretical characteristic frequency of the bearing.

Table 1 shows the theoretical characteristic frequencies at rated load based on the geometric structure of the bearing used in this work. These frequencies are Fundamental Train 
Frequency (FTF), Ball Spin Frequency (BSF), Outer Raceway Fault (ORF), and Inner Raceway Fault (IRF) frequencies and have been calculated as follows: [28-29].

Fundamental train frequency,

$$
F T F=\frac{f_{r}}{2}\left[-\left(\frac{B_{d}}{P_{d}}\right) \cos \theta\right] .
$$

Ball spin frequency,

$$
B S F=\frac{f_{r}}{2}\left(\frac{P_{d}}{B_{d}}\right)\left[1-\left(\frac{B_{d}}{P_{d}}\right) \cos \theta\right] .
$$

Outer raceway frequency,

$$
O R F=N \times(F T F) .
$$

Inner raceway frequency,

$$
I R F=N \times\left(f_{r}-(F T F)\right) .
$$

where, $f_{r}, B_{d}, P_{d}, \theta$ are the running speed frequency, the ball diameter, pitch diameter and contact angle respectively. Manufacturers often provide these defect frequencies in the bearing data sheet.

Table 1. The theoretical characteristics frequencies

\begin{tabular}{l|c}
\hline \multicolumn{1}{c|}{ Characteristics frequency } & Value (Hz) \\
\hline Running speed frequency, (Fr) & $29.23 \mathrm{~Hz}$ \\
\hline Fundamental train frequency, (FTF) & $11.64 \mathrm{~Hz}$ \\
\hline Ball spin frequency, (BSF) & $68.89 \mathrm{~Hz}$ \\
\hline Outer race fault frequency, (RFF), & $104.76 \mathrm{~Hz}$ \\
\hline Inner race fault frequency, (FTF) & $158.34 \mathrm{~Hz}$ \\
\hline
\end{tabular}

\section{Results and discussions}

In this paper, we have studied a bearing fault diagnosis method of an induction motor rolling bearing for its inner race and outer race. The proposed method is based on BDI and enveloped power spectrum using Hilbert transform, which, overcome the limitations of enveloped power spectrum. Fig. 8 shows the flow chart of calculation of BDI and enveloped power spectrum. Figs. 9 and 10 shows the calculated BDI for IRF and ORF up to three levels i.e. eight sub-bands or wavelet order. Further, a higher value of wavelet order is chosen to perform Hilbert transform and the spectral analysis. It is observed that the wavelet order 7 gives a higher value for both the cases IRF and ORF. These wavelet orders primarily may consist of 
the fault information. Based on this investigation the wavelet order 7 has been chosen for the enveloped power spectrum.

After performing Hilbert transform and the spectral analysis on the wavelet order 7, theoretical frequencies have been observed. The calculated characteristic frequencies are $158.34 \mathrm{~Hz}$ for the inner race fault and $104.76 \mathrm{~Hz}$ for the outer race fault as shown in Table 1. The BDI based enveloped power spectrum for the vibration data shows spectrum peaks values at $161.1 \mathrm{~Hz}$ for the inner race fault in Fig. 11 with a fault size equal to 0.007 and 0.021 inches. Frequency $323.7 \mathrm{~Hz}$ is the multiple of $161.1 \mathrm{~Hz}$ which also confirms the existence of the inner race fault in the rolling bearing. Similarly, frequency $107 \mathrm{~Hz}$ observed for the outer race fault in Fig. 12 with fault sizes of 0.007 inches and 0.021 inches and frequency $215.3 \mathrm{~Hz}$ multiple of $107 \mathrm{~Hz}$ which ensure the existence of the outer race fault in the rolling bearing. The obtained frequencies are near to the calculated frequency as per Table 2. Frequency peak $30.03 \mathrm{~Hz}$ is the running speed frequency which is also present in both Figs. 11, 12 and represents the rotational speed of the induction motor. The above analysis shows that energy of the wavelet orders is sensitive to the faults identification in bearings.

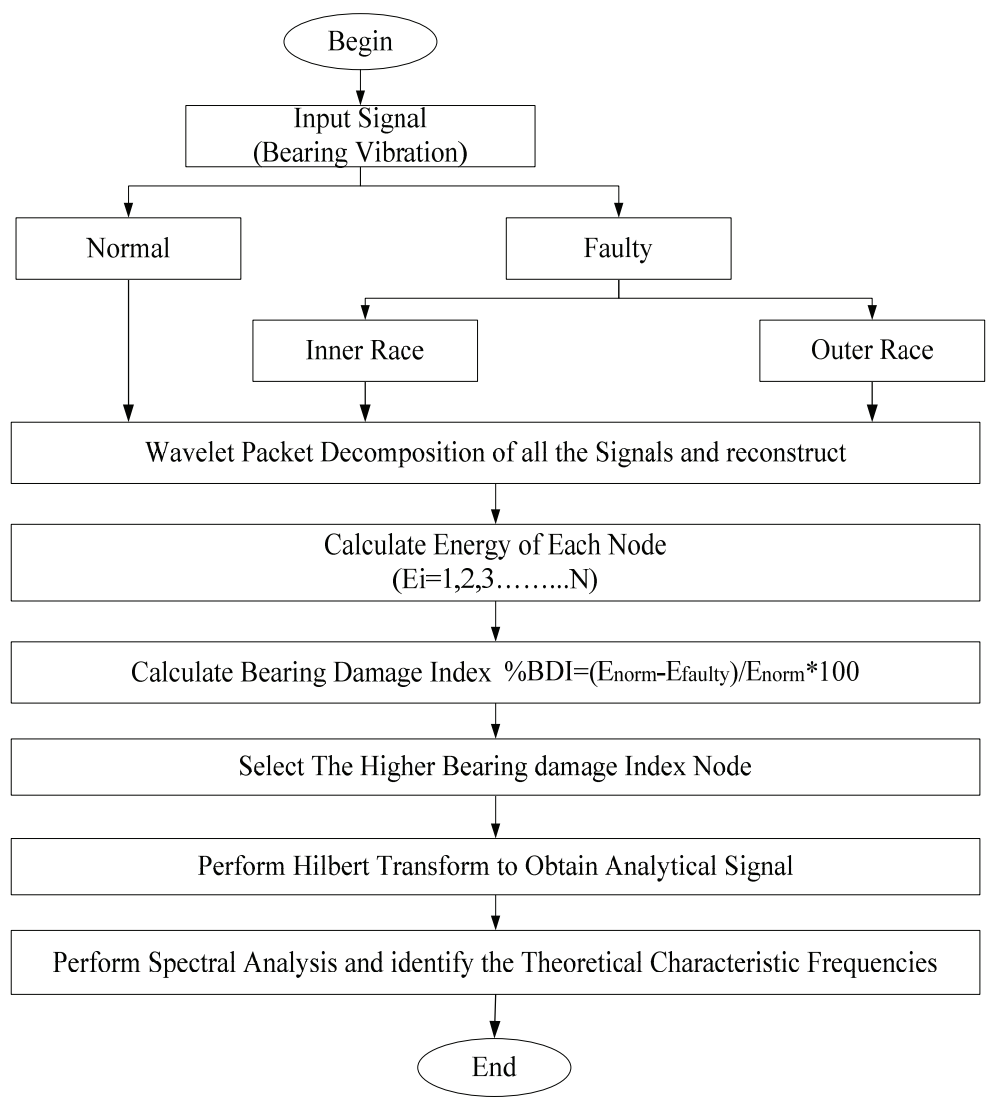

Fig. 8. Flow chart for calculation of bearing damage index 


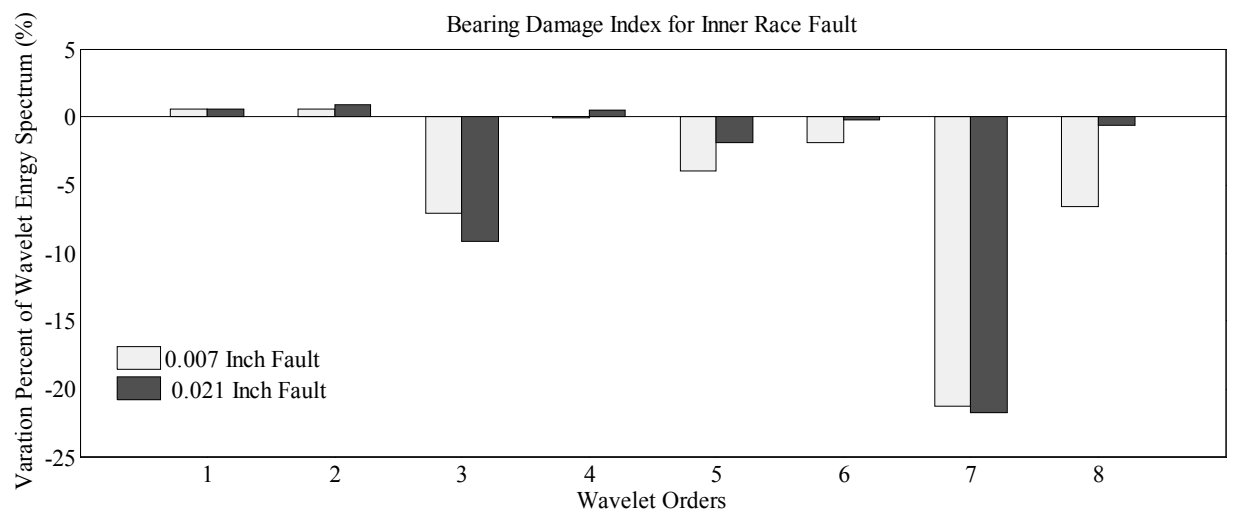

Fig. 9. Bearing damage index of inner race fault

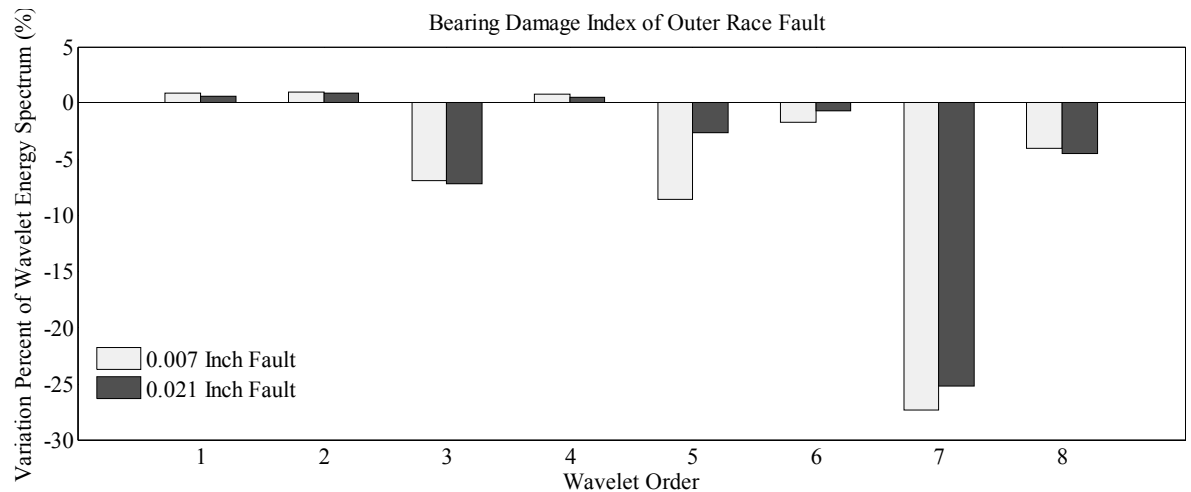

Fig. 10. Bearing damage index of outer race fault

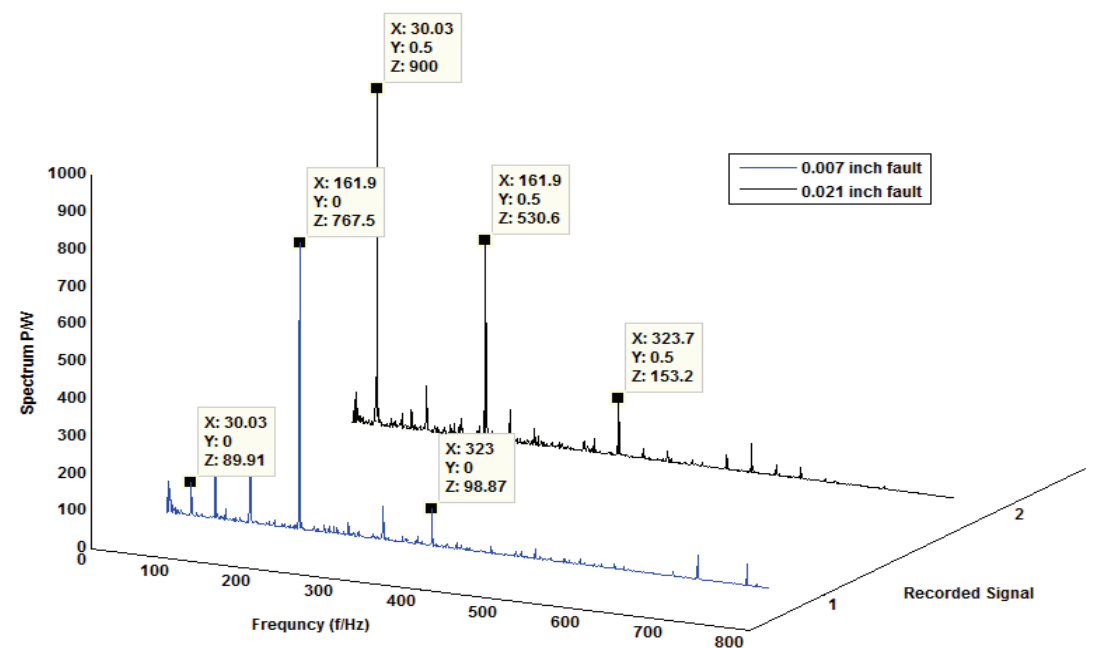

Fig. 11. Power spectrum of inner race fault 


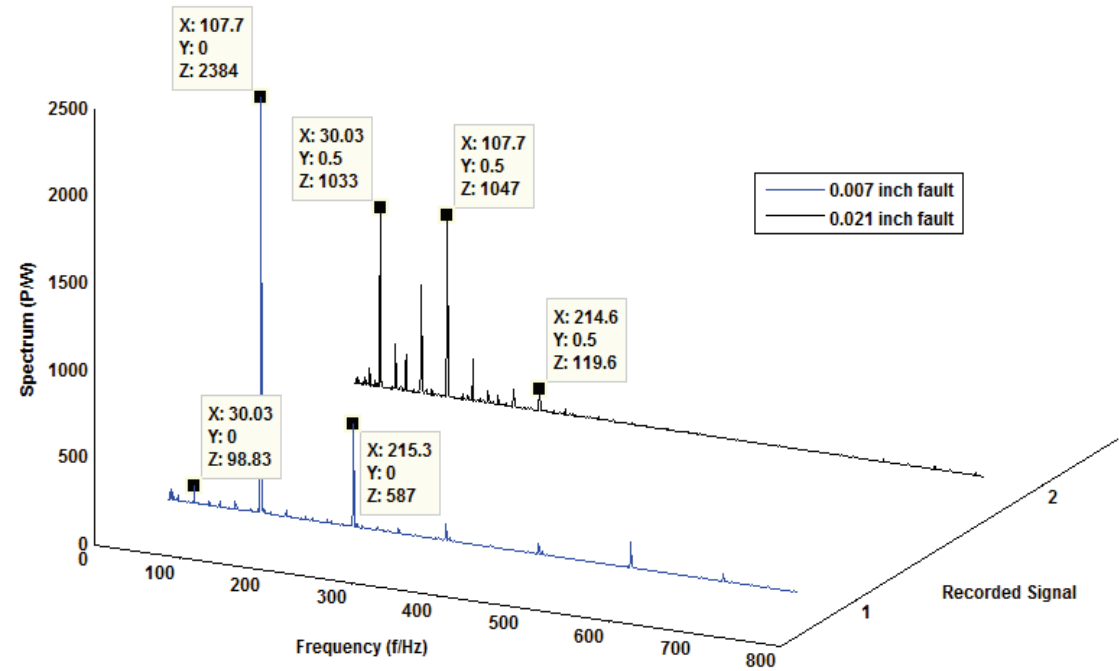

Fig. 12. Power spectrum of outer race fault

Table 2. Comparison of observed and theoretical frequency

\begin{tabular}{c|c|c}
\hline & Theoretical calculated frequency $(\mathbf{H z})$ & Observed frequency $(\mathbf{H z})$ \\
\hline IRF & $158.3 \mathrm{~Hz}$ & $161.9 \mathrm{~Hz}$ \\
\hline ORF & $104.7 \mathrm{~Hz}$ & $107.7 \mathrm{~Hz}$ \\
\hline
\end{tabular}

\section{Conclusions}

The parameters calculated from time domain are not capable of identifying the fault in the bearing. Results show that kurtosis and dimensionless quantities are more sensitive towards the fault severity but fail to find the location of the fault. A new approach based on BDI enveloped power spectrum is proposed. In order to calculate BDI, Wavelet Packet Transform (WPT) is used which is a time-frequency analysis and has great advantages in dealing with the vibration signature of the bearing health monitoring system. The BDI has been used as selection criteria of the wavelet order for enveloped power spectrum to find out the theoretical characteristic frequency for outer and inner race defective bearings from noisy vibration signals.

\section{References}

[1] Mehrjou M.R., Mariun N., Marhaban M.H., Rotor fault condition monitoring techniques for squirrel-cage induction machine - A review, Mech. Syst. Signal Process, no. 25, pp. 2827-2848 (2011).

[2] Wadhwani S., Gupta S.P., Kumar V., Wavelet based vibration monitoring for detection of faults in ball bearings of rotating machines, Journal Inst. Eng. (India)-EL, no. 86, pp. 77-81 (2005). 
[3] Purushotham V., Narayanan S., Prasad S.A.N., Multi-fault diagnosis of rolling bearing elements using wavelet analysis and hidden Markov model based fault recognition, NDT E Int., no. 38, pp. 654-664 (2005).

[4] Chandel A.K., Patel R.K., Bearing Fault Classification Based on Wavelet Transform and Artificial Neural Network, IETE Journal of Research, vol. 59, no. 3, pp. 219-225 (2013).

[5] Qin Y., Mao Y., Tang B., Vibration signal component separation by iteratively using basis pursuit and its application in mechanical fault detection, J. Sound Vib., no. 332, pp. 5217-5235 (2013).

[6] Djebala A., Ouelaa N., Detection of rolling bearing defects using discrete wavelet analysis, pp. 339-348 (2008).

[7] Gao R.X., Yan R., Non-stationary signal processing for bearing health monitoring, Int. J. of Manufacturing Research, vol. 1, no. 1, pp. 18-40 (2006).

[8] Gouda Kareem M., Joshua Tarbutton A., Hassan M.A. et al., A wavelet-based index for fault detection and its application in condition monitoring of helicopter drive-train components, Int. J. of Manufacturing Research, vol. 10, no.1, pp. 87-106 (2015).

[9] Randall R., Antoni J., Rolling element bearing diagnostics-A tutorial, Mech. Syst. Signal Process, no. 25 , pp. 485-520 (2011).

[10] Changting W., Gao R.X., Ruqiang Y., Malhi A., Rolling bearing defect severity assessment under varying operating conditions, Int. J. of Manufacturing Research, vol. 4, no. 1, pp. 37-56 (2009).

[11] Wadhwani S., Gupta S.P., Kumar V., Fault Classification for Rolling Element Bearing in Electric Machines, IETE J. Res. 54 (2011).

[12] Cabal-Yepez E., Romero-Troncoso R.J., Garcia-Perez A., Osornio-Rios R.A., Single-parameter fault identification through information entropy analysis at the startup-transient current in induction motors, Electr. Pow. Syst. Res, vol. 89, pp. 64-69 (2012).

[13] Choudary A., Tondon N., Vibration response of rolling element bearings in a rotor bearing system to a local defect under radial load, Transactions of ASME, vol. 128, pp. 252-61(2006).

[14] Sreejith B., Verma A.K., Srividya A., Fault diagnosis of rolling element bearing using time-domain features and neural networks, IEEE Region 10 Colloquium and the Third ICIIS, Kharagpur, India, pp. 6-11 (2008).

[15] Miao Q., Wang D., Huang H.Z., Identification of characteristic components in frequency domain from signal singularities, Rev. Sci. Instrum, 81: 035113 (2010).

[16] Nikolaou N.G., Antoniadis I.A., Rolling element bearing fault diagnosis using wavelet packets, NDT \& E International, vol. 35, pp. 197-205 (2002).

[17] Yen G.G., Lin K.-C., Wavelet Packet Feature Extraction for Vibration monitoring, Proceedings of the IEEE Conference on Control Applications, pp. 1573-1578 (1999).

[18] Powalka B., Dhupia J.S., Ulsoy A.G., Katz R., Identification of machining force model parameters from acceleration measurements, Int. J. of Manufacturing Research, vol. 3, no. 3, pp. 265-284 (2008).

[19] Hong H., Liang M., Fault severity assessment for rolling element bearings using the Lempel-Ziv complexity and continuous wavelet transform, Journal of Sound and Vibration, vol. 320, pp. 452-468 (2009).

[20] Case Western Reserve University, Bearing data center [online]: URL:http://www.eecs.cwru.edu/laboratory/bearing/download.htm, accessed 2011.

[21] Collacott R.A., Mechanical fault diagnosis and condition monitoring, London, Chapman and Hall (1977).

[22] Mathew J., Alfredson R.J., The condition monitoring of rolling element bearings using vibration analysis, Journal of Vibration, Acoustics Stress and Reliability in Design, vol. 106, pp. 447-53 (1984).

[23] Pachaud C., Salvetat R., Fray C., Crest factor and kurtosis contributions to identify defects inducing periodical impulsive forces, Mechanical Systems and Signal Processing, vol. 11, pp. 903-916 (1997).

[24] Heng R.B.W., Nor M.J.M., Statistical Analysis of Sound and Vibration Signals for Monitoring Rolling Element Bearing Condition, Applied Acoustics, vol. 53, pp. 211-226 (1998). 
[25] McFadden P. ., Smith J.D., Vibration monitoring of rolling element bearings by the high frequency resonance technique-a review, Tribology International, vol. 17, pp. 3-10 (1984).

[26] Wowk V., Machinery Vibration Measurement and Analysis, McGraw-Hill, New York (1991)

[27] Liu Q., Chen F., Zhou Z., Wei Q., Fault Diagnosis of Rolling Bearing Based on Wavelet Package Transform and Ensemble Empirical Mode Decomposition, (2013).

[28] Wang D., Zhang W., Fault diagnosis study of ball bearing based on wavelet packet transform, China Mechanical Engineering, vol. 23, no. 3, pp. 295-298 (2012).

[29] Jiang F., Li W., Wang Z., Zhu Z., Fault Severity Estimation of Rotating Machinery Based on Residual Signals, Adv. Mech. Eng., vol. 2012, pp. 1-8 (2012). 